\title{
Faecal microbial metabolites of proteolytic and saccharolytic fermentation in relation to degree of insulin resistance in adult individuals
}

\author{
M.A. González Hernández, E.E. Canfora and E.E. Blaak* \\ Human Biology, School of Nutrition and Translational Research in Metabolism (NUTRIM), Maastricht University, \\ Universiteitssingel 40,6229 ET Maastricht, the Netherlands; e.blaak@maastrichtuniversity.nl
}

Received: 3 September 2020 / Accepted: 8 January 2021

(c) 2021 Wageningen Academic Publishers

OPEN ACCESS @(1)@(2) RESEARCH ARTICLE

\begin{abstract}
The gut microbiota may affect host metabolic health through microbial metabolites. The balance between the production of microbial metabolites by saccharolytic and proteolytic fermentation may be an important determinant of metabolic health. Amongst the best-studied saccharolytic microbial metabolites are the short-chain fatty acids acetate, propionate and butyrate. However, human data on the role of other microbial fermentation by-products in metabolic health are greatly lacking. Therefore, we compared in a cross-sectional study the faecal microbial metabolites (caproate, lactate, valerate, succinate, and the branched-chain fatty acids (BCFA) (isobutyrate, isovalerate)) between insulin sensitive (homeostatic model assessment of insulin resistance (HOMA-IR), HOMA-IR<1.85, IS) and insulin resistant (HOMA-IR>1.85, IR) individuals. Additionally, we assessed the relationships between faecal metabolites and markers of metabolic health including fasting glucose, insulin, free fatty acids, insulin resistance (HOMA-IR) and fasting substrate oxidation in 86 individuals with a wide range of body mass index. Faecal metabolite concentrations did not significantly differ between IS and IR. Furthermore, there were no associations between microbial metabolites and metabolic health markers, except for a slight positive association of isovalerate with carbohydrate oxidation (E\%, std $\beta 0.194, P=0.011)$ and fat oxidation (E\%, std $\beta-0.075, P=0.047)$, also after adjustment for age, sex and BMI. In summary, faecal caproate, lactate, valerate, succinate, and BCFA (isobutyrate, isovalerate) were not different between IR and IS individuals, nor was there any association between these faecal metabolites and parameters of metabolic health. Further human intervention studies are warranted to investigate the role of these microbially-derived fermentation products and their kinetics in metabolic health and insulin sensitivity.
\end{abstract}

Keywords: gut-derived metabolites, insulin sensitivity, excessive body weight

\section{Introduction}

Metabolic health is impacted by gut health maintenance which is intricately modulated through various mechanisms, including the preservation of a balanced microbial composition and functionality (Canfora et al., 2015). In addition, a high microbial diversity has been linked to gut health as well as to an improved insulin sensitivity and metabolic health in various animal and human studies (Castaner et al., 2018; Koliada et al., 2017; Ley et al., 2005; Mariat et al., 2009; Schwiertz et al., 2010; Turnbaugh et al., 2006). In contrast, the presence of gut dysbiosis has been linked to the development of obesity and its complications (Shen et al., 2013).
Metabolites derived from the microbial fermentation of indigestible foods play an important role in the microbeshost metabolic crosstalk. In the proximal colon, microbial fermentation of mainly indigestible carbohydrates (saccharolytic fermentation) produces short chain fatty acids (SCFA, acetate, propionate and butyrate) as well as other metabolites (e.g. lactate, succinate, valerate, caproate) and gases (e.g. methane, carbon dioxide and hydrogen) (Canfora et al., 2015; Koh et al., 2016). The distal portion of the colon specialises more in proteolytic fermentation (residual peptides and proteins) and produces a wide variety of metabolites including phenolic compounds, indoles, hydrogen sulphide as well as branched chain fatty acids (BCFA), such as isovalerate and isobutyrate (Canfora et 
al., 2019; Mika et al., 2016; Ran-Ressler et al., 2014). In general, the majority of microbial metabolites derived from proteolytic fermentation are associated with adverse gut and metabolic health effects. An increased production of proteolytic fermentation by-products elicited by high protein diets (HPD) or low-fibre diets may lead to altered production of microbial derived metabolites (e.g. increase faecal BCFA and decrease faecal SCFA), alterations in gut microbiota, colonic epithelium as well as impaired detoxification capacity of gut mucosa and increased inflammation (Blachier et al., 2019).

Furthermore, in human small-scale observational studies, faecal BCFA concentrations have been reported to be higher in individuals with obesity (Tiihonen et al., 2010) and hypercholesterolemia (Granado-Serrano et al., 2019) as well as associated to non-alcoholic fatty liver disease (NAFLD) progression (Da Silva et al., 2018). Interestingly, the gut microbiome from obese individuals has shown a higher biosynthetic capacity for BCFA precursors, branched chain amino acids (Ridaura et al., 2013), which circulating concentrations have been related to tissue specific insulin resistance in obese individuals (Vogelzangs et al., 2020) as well as with type 2 Diabetes mellitus (T2DM) (Gannon et al., 2018; Newgard et al., 2009). Currently, there is a lack of studies that investigate the role of microbial fermentation by-products besides the major SCFA acetate, propionate and butyrate. The balance between saccharolytic fermentation products with positive effects and proteolytic fermentation products with overall adverse effects on metabolic health may be important in determining the net effect on energy and substrate metabolism, insulin sensitivity and metabolic health, as recently reviewed (Canfora et al., 2019). Therefore, we hypothesised that faecal microbial metabolite concentrations (e.g. BCFA) are different between more pronounced insulin resistant and more pronounced insulin sensitive phenotypes. In the present cross-sectional study, we investigated whether faecal microbial metabolites (caproate, lactate, valerate, succinate, and the BCFA (isobutyrate, isovalerate)) varied based on HOMA-IR by comparing values in a more insulin sensitive and more insulin resistant group, as determined by the median HOMA-IR value (1.85) of our population. Secondly, we assessed the associations of these faecal metabolites with fasting glucose, insulin, free fatty acids (FFA), insulin resistance ((homeostatic model assessment of insulin resistance (HOMA-IR)) and fasting substrate oxidation in a continuous analysis the whole cohort.

\section{Materials and methods}

\section{Study participants}

After meeting the inclusion criteria, a cohort of 86 Caucasian men and women aged 20-69 years with a BMI between 19.2 and $35.2 \mathrm{~kg} / \mathrm{m}^{2}$ from the vicinity of Maastricht was divided based on the HOMA-IR median (1.85) in insulin sensitive (IS, HOMA-IR $<1.85$ ) and insulin resistant individuals (IR, HOMA-IR $>1.85$ ). Additionally, in the total cohort, associations between faecal metabolites and parameters of metabolic health were assessed. Eligibility of the participants was assessed via a general health questionnaire, medical history and anthropometry during an initial screening visit. Exclusion criteria were as follows: use of antibiotics, prebiotics, or probiotics 3 months before or during the study, diagnosis of T2DM, gastrointestinal or cardiovascular diseases, abdominal surgery, participants with life expectancy shorter than 5 years, alcohol or drug abuse and participants following a hypocaloric diet. Participants did not use $\beta$-blockers, lipid- or glucoselowering drugs, antioxidants, or chronic corticosteroids. All protocols were reviewed and approved by the local Medical Ethical Committee (MUMC+) and conducted in accordance with the Declaration of Helsinki (revised version, October 2008, Seoul, South Korea). Written informed consent was obtained from all participants.

\section{Study design}

This cross-sectional analysis included metabolic parameters as well as faecal metabolites (caproate, lactate, valerate, succinate, BCFA) of previously performed interventions (Canfora and Blaak, 2018; Müller et al., 2020; Van der Beek et al., 2018). The drop-out in these intervention studies was on average $10-15 \%$. In the present study, we collated and analysed study data at baseline and thus prior to the respective interventions. In all studies, sample collection and measurements were conducted according to the same standard operating procedures. Two days prior to the baseline investigation day, participants were asked to refrain from intense physical activity and alcohol consumption. On the evening before the investigation day, subjects were provided with a standardised meal composed of $65 \mathrm{E} \%$ carbohydrates with a low fibre content, $20 \mathrm{E} \%$ fat and $15 \mathrm{E} \%$ protein to ensure a standard meal with a low amount of dietary fibre the evening prior to the baseline measurements. 


\section{Used data sets}

For this analysis we included baseline data from the following intervention human in vivo studies. The data set includes an intervention study with arabinoxylanoligosacharide (AXOS) in healthy participants with slow gastrointestinal transit (Clinical trial No. NCT02491125) (Müller et al., 2020), an intervention study with prebiotic inulin in overweight to obese individuals on substrate metabolism (Clinical trial No. NCT03711383) (Van der Beek et al., 2018) and an intervention study with beta glucan in lean-overweight individuals (Clinical trial No. NCT03714646) (Canfora and Blaak, 2018).

\section{Baseline investigation day}

After an overnight fast ( $>10 \mathrm{~h})$, participants came to the laboratory by car or public transport. Anthropometry was measured including height, weight and waist to hip ratio. After inserting a cannula into the antecubital vein, blood samples were taken to measure plasma metabolites in the fasted state. After the blood sampling, participants were in a resting, half-supine position and fasting substrate oxidation was measured for 30 min using an open circuit ventilated hood system (Omnical, MUMC+, Maastricht, the Netherlands). Fat and carbohydrate oxidation were calculated according to the equations of De Weir and Frayn (Frayn, 1983; De Weir, 1949), assuming that protein oxidation accounted for $15 \%$ of total energy expenditure. Fat and carbohydrate oxidation are expressed as percentage of energy expenditure.

\section{Analysis of faecal microbial metabolites}

Faecal samples were collected at home and stored in the subjects' freezer at $-20{ }^{\circ} \mathrm{C}$ maximum of two days before the baseline investigation day, transported on dry ice, and stored on arrival at the university at $-80^{\circ} \mathrm{C}$. BCFA, lactate, succinate, caproate and valerate were measured using gas chromatography-mass spectrometry as described previously (Garcia-Villalba et al., 2012).

\section{Blood collection and biochemical analysis}

Blood was collected in pre-chilled EDTA tubes (0.2 mol/l EDTA; Sigma, Dorset, UK) for insulin, glucose, FFA, analyses during fasting conditions. Plasma glucose and FFA were determined using commercially available reagent kits for glucose (Glucose HK CP; Horiba ABX Pentra, Montpellier, France) and FFA (NEFA-HR (2) assay, Wako, Sopachem BV, Ochten, the Netherlands). Plasma insulin was determined with a commercially available radioimmunoassay (RIA) kit (HI-14K Human Insulin specific RIA HI-14K; Millipore Merck, Darmstadt, Germany) according to the manufacture's protocol. HOMAIR was calculated as the product of (glucose $(\mathrm{mmol} / \mathrm{l}) \times$ insulin $(\mu \mathrm{U} / \mathrm{ml}) / 22.5)$, using fasting values (Matthews $e t$ al., 1985).

\section{Statistical analysis}

First, we divided the total cohort into two groups based on the HOMA-IR median (1.85), insulin sensitive (IS, HOMAIR $<1.85$ ) and insulin resistant individuals (IR, HOMAIR $>1.85$ ) to compare the microbial metabolites on group level. The normality of data was assessed with the Gaussian distribution and Kolmogorov-Smirnov procedure. Variables that were not normally distributed were $\ln$-transformed. In case of missing data, the participant was excluded from the analysis. Differences between IS and IR characteristics were analysed using a Student's independent samples t-test. Next, we used simple/multiple linear regression to investigate the associations between faecal metabolites (as independent variables) and metabolic parameters (as dependent variables) in the whole cohort. Multiple linear regression models were adjusted for the covariates age, sex and BMI. All data were analysed using SPSS 22.0 (IBM, Armonk, NY, USA) with significance set at $P<0.05$.

\section{Results}

The mean age of the participants in our cohort was $45.8 \pm 15$ years and $60.5 \%$ of participants were male. To study differences between the aforementioned faecal metabolites including proteolytic fermentation by-products (BCFA) in relation to insulin sensitivity on group level, we divided the total cohort into two groups based on the HOMA-IR median (1.85), insulin sensitive (IS, HOMA-IR $<1.85$ ) and insulin resistant individuals (IR, HOMA-IR $>1.85$ ). While there were differences between groups in body weight, BMI, fasting insulin, fasting glucose, 2-h glucose and HOMA-IR, there were no differences in faecal metabolites between IS and IR groups (Table 1). We found a weak association of faecal isovalerate concentrations with carbohydrate oxidation $\mathrm{E} \%$ (std $\beta$ 0.194, $P=0.011$ ) and fat oxidation $\mathrm{E} \%$ (std $\beta-0.075, P=0.047$ ) in the whole cohort (Table 2), which was maintained after adjustment for age, sex and BMI. However, we did not find further associations between the faecal metabolites valerate, caproate, succinate, lactate and BCFA concentrations with fasting metabolites (glucose, insulin, FFA), HOMA-IR and fasting substrate oxidation in the whole cohort. 
Table 1. Characteristics of insulin sensitive (HOMA-IR<1.85) and insulin resistant (HOMA-IR>1.85) individuals. ${ }^{1}$

\begin{tabular}{|c|c|c|c|c|c|}
\hline \multirow[t]{2}{*}{ Parameter } & \multicolumn{2}{|c|}{ Insulin sensitive $(n=43)$} & \multicolumn{2}{|c|}{ Insulin resistant $(n=43)$} & \multirow[t]{2}{*}{$P$-value } \\
\hline & Mean \pm SD & Range & Mean \pm SD & Range & \\
\hline $\operatorname{Sex}(F / M)$ & $18 / 25$ & & $16 / 27$ & & \\
\hline Age (y) & $46 \pm 15$ & $20-66$ & $46 \pm 16$ & $20-69$ & 0.850 \\
\hline Body weight (kg) & $73.7 \pm 11.3$ & $52-103$ & $83.8 \pm 15.2$ & $57-144$ & 0.000 \\
\hline BMI $\left(\mathrm{kg} / \mathrm{m}^{2}\right)$ & $24.0 \pm 2.2$ & $19-28$ & $27.1 \pm 3.6$ & $19-35$ & 0.000 \\
\hline Waist:hip ratio & $0.85 \pm 0.11$ & $0.64-1.07$ & $0.89 \pm 0.12$ & $0.70-1.07$ & 0.123 \\
\hline HOMA-IR & $1.3 \pm 0.3$ & $0.6-1.9$ & $3.0 \pm 1.4$ & $1.9-9.0$ & 0.000 \\
\hline Fasting plasma insulin (mU/l) & $5.8 \pm 1.5$ & $2-9$ & $12.3 \pm 5.8$ & $7-39$ & 0.000 \\
\hline Fasting plasma glucose (mmol/l) & $4.9 \pm 0.4$ & $4-6.3$ & $5.5 \pm 0.8$ & $4-7.4$ & 0.000 \\
\hline $2 \mathrm{~h}$ glucose $(\mathrm{mmol} / \mathrm{l})$ & $4.7 \pm 1.8$ & $2.1-11.0$ & $6.2 \pm 2.3$ & $2-10.8$ & 0.002 \\
\hline Fasting plasma free fatty acids ( $\mu \mathrm{mol} / \mathrm{l})$ & $517 \pm 214$ & $117-949$ & $468 \pm 146$ & $96-759$ & 0.222 \\
\hline Faecal isobutyrate $(\mu \mathrm{mol} / \mathrm{g})$ & $1.8 \pm 0.9$ & $0.6-4.3$ & $2.0 \pm 1.3$ & $0.1-5.4$ & 0.586 \\
\hline Faecal valerate $(\mu \mathrm{mol} / \mathrm{g})$ & $1.7 \pm 1.5$ & $0.1-8.4$ & $1.8 \pm 1.5$ & $0.1-5.3$ & 0.857 \\
\hline Faecal isovalerate $(\mu \mathrm{mol} / \mathrm{g})$ & $2.7 \pm 1.6$ & $0.1-6.3$ & $2.7 \pm 2.6$ & $0.1-12.8$ & 0.988 \\
\hline Faecal caproate $(\mu \mathrm{mol} / \mathrm{g})$ & $1.0 \pm 0.8$ & $0.1-3.1$ & $1.3 \pm 1.5$ & $0.1-7.1$ & 0.314 \\
\hline Faecal succinate $(\mu \mathrm{mol} / \mathrm{g})$ & $1.3 \pm 1.0$ & $0-3.6$ & $1.8 \pm 2.6$ & $0.1-15.3$ & 0.289 \\
\hline Faecal lactate $(\mu \mathrm{mol} / \mathrm{g})$ & $1.0 \pm 1.1$ & $0.1-4.7$ & $0.9 \pm 0.9$ & $0.1-3.3$ & 0.706 \\
\hline Energy intake (kcal/d) & $1,924 \pm 503$ & $1,065-3,600$ & $1,957 \pm 471$ & $1,265-3,165$ & 0.786 \\
\hline Carbohydrate intake, E\% & $46 \pm 7$ & $32-63$ & $46 \pm 6$ & $34-60$ & 0.905 \\
\hline Fat intake, $\mathrm{E} \%$ & $34 \pm 7$ & $16-50$ & $35 \pm 6$ & $23-49$ & 0.455 \\
\hline Protein intake, E\% & $17 \pm 4$ & $10-27$ & $17 \pm 4$ & $9-25$ & 0.610 \\
\hline Dietary fibre (g/MJ) & $2.4 \pm 0.8$ & $1.1-4.1$ & $2.4 \pm 0.6$ & $1.4-4.3$ & 0.948 \\
\hline
\end{tabular}

\section{Discussion}

In this cross-sectional analysis, we showed that the faecal concentrations of BCFA and other faecal metabolites (lactate, succinate, caproate and valerate) were not different between IS and IR individuals. In addition, we could not find a relationship between these microbiota-derived metabolites and insulin resistance and metabolic health parameters in a continuous analysis in the total group.

Our findings are in line with a study that did not find differences in faecal BCFA concentrations between overweight/obese and healthy individuals (Fernandes et al., 2014). In contrast, another cross-sectional study showed increased total faecal BCFA (isovalerate, isobutyrate and 2 methylbutyrate) and valerate concentrations in obese (30$37 \mathrm{BMI} \mathrm{kg} / \mathrm{m}^{2}$ ) hyperinsulinaemic individuals as compared to non-obese normo-insulinemic individuals (Tiihonen et al., 2010). Furthermore, increased faecal isobutyrate concentrations have been previously related to NAFLD progression in both rodents (Le Roy et al., 2013) and humans (Da Silva et al., 2018) and higher faecal BCFA have been associated with hypercholesterolemia (GranadoSerrano et al., 2019).
In view of the above inconsistent data, it is important to consider that faecal concentrations depend on various factors including microbial community (Feng et al., 2018), intestinal transit time (Müller et al., 2018), diet (Den Besten et al., 2013; Tang et al., 2019), age (Nagpal et al., 2018) and lifestyle (Zhong et al., 2019). Additionally, gut-derived circulating metabolite concentrations may relate more strongly with changes in whole body metabolic markers than faecal concentrations as we have previously suggested for SCFA (Müller et al., 2019). Of note, obese individuals have been reported to have lower circulating isobutyrate and higher isovalerate concentrations as compared to healthy individuals (Aragonès et al., 2020). In addition, an in vitro study using rat and human adipocytes showed that both BCFA (isobutyrate and isovalerate) inhibited cytosolic (intracellular) lipolysis and lipogenesis using supraphysiological concentrations $(10 \mathrm{mmol} / \mathrm{l})$ (Heimann et al., 2016).

Thus, although our study did not show differences in faecal BCFA between metabolic phenotypes, other studies $(38,39)$ may suggest alteration in circulating BCFA in metabolically compromised individuals and possible tissue-specific 
Table 2. Relationship between faecal metabolites with metabolic markers. ${ }^{1}$

\begin{tabular}{|c|c|c|c|c|c|c|c|c|}
\hline \multirow[t]{2}{*}{ Metabolite } & \multicolumn{4}{|c|}{ Faecal isobutyrate } & \multicolumn{4}{|l|}{ Faecal valerate } \\
\hline & std $\beta$ & $P$-value & std $\beta$ adj & $P$-value & std $\beta$ & $P$-value & std $\beta$ adj & $P$-value \\
\hline $\mathrm{FFA}, \mu \mathrm{mol} / /$ & $-0.079 \pm 0.061$ & 0.196 & $-0.070 \pm 0.056$ & 0.211 & $-0.008 \pm 0.045$ & 0.858 & $0.015 \pm 0.042$ & 0.713 \\
\hline Insulin, mU/I & $-0.007 \pm 0.057$ & 0.917 & $0.023 \pm 0.056$ & 0.686 & $-0.003 \pm 0.051$ & 0.950 & $-0.005 \pm 0.044$ & 0.911 \\
\hline HOMA-IR & $-0.013 \pm 0.071$ & 0.855 & $0.026 \pm 0.057$ & 0.646 & $0.004 \pm 0.055$ & 0.939 & $-0.004 \pm 0.046$ & 0.931 \\
\hline Glucose, mmol/l & $-0.008 \pm 0.015$ & 0.596 & $0.002 \pm 0.013$ & 0.865 & $0.006 \pm 0.011$ & 0.611 & $0.000 \pm 0.009$ & 0.976 \\
\hline Fat, E\% & $-0.078 \pm 0.042$ & 0.068 & $-0.073 \pm 0.042$ & 0.086 & $-0.008 \pm 0.032$ & 0.813 & $-0.002 \pm 0.032$ & 0.957 \\
\hline \multirow[t]{3}{*}{$\mathrm{CHO}, \mathrm{E} \%$} & $0.123 \pm 0.082$ & 0.140 & $0.117 \pm 0.083$ & 0.167 & $0.045 \pm 0.062$ & 0.468 & $0.039 \pm 0.063$ & 0.539 \\
\hline & \multicolumn{4}{|c|}{ Faecal isovalerate } & \multicolumn{4}{|c|}{ Faecal caproate } \\
\hline & $s t d \beta$ & $P$-value & $\operatorname{std} \beta$ adj & $P$-value & $\operatorname{std} \beta$ & $P$-value & std $\beta$ adj & $P$-value \\
\hline $\mathrm{FFA}, \mu \mathrm{mol} / \mathrm{l}$ & $-0.018 \pm 0.053$ & 0.742 & $-0.029 \pm 0.049$ & 0.556 & $-0.016 \pm 0.046$ & 0.731 & $-0.007 \pm 0.043$ & 0.866 \\
\hline Insulin, mU/I & $-0.030 \pm 0.061$ & 0.625 & $-0.014 \pm 0.052$ & 0.782 & $0.092 \pm 0.046$ & 0.051 & $0.073 \pm 0.040$ & 0.075 \\
\hline HOMA-IR & $-0.028 \pm 0.066$ & 0.672 & $0.001 \pm 0.054$ & 0.979 & $0.094 \pm 0.048$ & 0.057 & $0.070 \pm 0.040$ & 0.084 \\
\hline Glucose, mmol/l & $0.000 \pm 0.014$ & 0.982 & $0.015 \pm 0.012$ & 0.216 & $0.000 \pm 0.010$ & 0.981 & $-0.003 \pm 0.008$ & 0.691 \\
\hline Fat, E\% & $-0.073 \pm 0.037$ & 0.047 & $-0.075 \pm 0.037$ & 0.047 & $-0.011 \pm 0.032$ & 0.738 & $-0.011 \pm 0.031$ & 0.725 \\
\hline \multirow[t]{3}{*}{$\mathrm{CHO}, \mathrm{E} \%$} & $0.187 \pm 0.074$ & 0.012 & $0.194 \pm 0.075$ & 0.011 & $0.003 \pm 0.067$ & 0.960 & $0.009 \pm 0.057$ & 0.892 \\
\hline & \multicolumn{4}{|c|}{ Faecal succinate } & \multicolumn{4}{|l|}{ Faecal lactate } \\
\hline & $s t d \beta$ & $P$-value & std $\beta$ adj & $P$-value & $s t d \beta$ & $P$-value & std $\beta$ adj & $P$-value \\
\hline $\mathrm{FFA}, \mu \mathrm{mol} / /$ & $0.003 \pm 0.049$ & 0.951 & $-0.052 \pm 0.045$ & 0.257 & $0.040 \pm 0.050$ & 0.419 & $-0.032 \pm 0.048$ & 0.507 \\
\hline Insulin, mU/I & $0.009 \pm 0.052$ & 0.867 & $0.001 \pm 0.045$ & 0.981 & $0.017 \pm 0.052$ & 0.745 & $-0.015 \pm 0.048$ & 0.747 \\
\hline HOMA-IR & $0.001 \pm 0.055$ & 0.979 & $0.004 \pm 0.045$ & 0.929 & $-0.005 \pm .055$ & 0.925 & $-0.030 \pm 0.541$ & 0.541 \\
\hline Glucose, $\mathrm{mmol} / \mathrm{l}$ & $-0.008 \pm 0.012$ & 0.508 & $0.004 \pm 0.010$ & 0.719 & $-0.023 \pm 0.011$ & 0.031 & $-0.015 \pm 0.010$ & 0.133 \\
\hline Fat, E\% & $-0.015 \pm 0.035$ & 0.675 & $-0.031 \pm 0.036$ & 0.390 & $0.019 \pm 0.035$ & 0.584 & $-0.006 \pm 0.037$ & 0.872 \\
\hline $\mathrm{CHO}, \mathrm{E} \%$ & $-0.044 \pm 0.070$ & 0.535 & $-0.033 \pm 0.073$ & 0.652 & $-0.032 \pm 0.072$ & 0.658 & $0.002 \pm 0.078$ & 0.976 \\
\hline
\end{tabular}

${ }^{1} \mathrm{Std} \beta$ (adj) $=$ standardised $\beta$ coefficient + standard error of coefficient of faecal branched chain fatty acids (isobutyrate, isovalerate), valerate, caproate, succinate and lactate as dependent variable in a simple regression and multiple regression analysis adjusted for age, sex and body mass index. $\mathrm{E} \%=$ percentage of energy expenditure; FFA = free fatty acids, $\mathrm{HOMA}-\mathrm{IR}=$ homeostatic model assessment of insulin resistance; $\mathrm{CHO}=$ carbohydrate oxidation .

metabolic effects. More research investigating BCFA dynamics may shed light on whether BCFA handling is disturbed in different metabolic phenotypes and/or whether BCFA need to enter the circulation to exert metabolic effects.

Of note, various human studies reported that a HPD could increase faecal BCFA/SCFA ratio through a higher proteolytic fermentation, possibly inducing adverse health consequences in the long-term (Blachier et al., 2019; Russell et al., 2011). Additionally, a human study reported that a high fibre diet (resistant starch type 2 and arabinoxylan fibres) increased saccharolytic/proteolytic fermentation ratio while a Western diet did not (Hald et al., 2016). Collectively, current literature shows that the capacity of dietary interventions to modulate saccharolytic/ proteolytic fermentation may have an impact on gut and metabolic health. A further interesting aspect to consider in future research is the microbial phenotype. For example, a study showed that differences in saccharolytic/proteolytic fermentation ratio may depend on microbial enterotype (microbial community stratification in Bacteroides, Prevotella, Ruminococcus) (Arumugam et al., 2011). For instance, the Bacteroides enterotype has been linked to higher consumption of protein and saturated fats, whereas Prevotella enterotype has been associated to a lower protein intake (Wu et al., 2011). 


\section{Conclusions}

In conclusion, the present data do not show any alteration in proteolytic fermentation metabolites (faecal BCFA) and the saccharolytic metabolites lactate, succinate, valerate and caproate with degree of insulin resistance. Future nutritional interventions with the aim to modulate saccharolytic/ proteolytic fermentation should measure the kinetics of these metabolites as well as plasma concentrations taking into account the metabolic (Bouter et al., 2018; Hansen et al., 2020; Lim et al., 2016) and microbial phenotypes (Arumugam et al., 2011; Holscher, 2017; KovatchevaDatchary et al., 2015).

\section{Conflict of interest}

The authors declare no conflict of interest.

\section{References}

Aragonès, G., Colom-Pellicer, M., Aguilar, C., Guiu-Jurado, E., Martínez, S., Sabench, F., Antonio Porras, J., Riesco, D., Del Castillo, D., Richart, C. and Auguet, T., 2020. Circulating microbiota-derived metabolites: a liquid biopsy? International Journal of Obesity 44: 875-885. https://doi.org/10.1038/s41366-019-0430-0

Arumugam, M., Raes, J., Pelletier, E., Le Paslier, D., Yamada, T., Mende, D.R., Fernandes, G.R., Tap, J., Bruls, T., Batto, J.-M., Bertalan, M., Borruel, N., Casellas, F., Fernandez, L., Gautier, L., Hansen, T., Hattori, M., Hayashi, T., Kleerebezem, M., Kurokawa, K., Leclerc, M., Levenez, F., Manichanh, C., Nielsen, H.B., Nielsen, T., Pons, N., Poulain, J., Qin, J., Sicheritz-Ponten, T., Tims, S., Torrents, D., Ugarte, E., Zoetendal, E.G. Wang, J., Guarner, F., Pedersen, O., De Vos, W.M., Brunak, S., Doré, J., Antolín, M., Artiguenave, F., Blottiere, H.M., Almeida, M., Brechot, C., Cara, C., Chervaux, C., Cultrone, A., Delorme, C., Denariaz, G., Dervyn, R., Foerstner, K.U., Friss, C., Van de Guchte, M., Guedon, E., Haimet, F., Huber, W., Van Hylckama-Vlieg, J., Jamet, A., Juste, C., Kaci, G., Knol, J., Kristiansen, K., Lakhdari, O., Layec, S., Le Roux, K., Maguin, E., Mérieux, A., Melo Minardi, R., M'Rini, C., Muller, J., Oozeer, R., Parkhill, J., Renault, P., Rescigno, M., Sanchez, N., Sunagawa, S., Torrejon, A., Turner, K., Vandemeulebrouck, G., Varela, E., Winogradsky, Y., Zeller, G., Weissenbach, J., Ehrlich, S.D., Bork, P. and the MetaHIT consortium, 2011. Enterotypes of the human gut microbiome. Nature 473: 174-180. https://doi.org/10.1038/ nature09944.

Blachier, F., Beaumont, M., Portune, K.J., Steuer, N., Lan, A., Audebert, M., Khodorova, N., Andriamihaja, M., Airinei, G., Benamouzig, R., Davila, A.-M., Armand, L., Rampelli, S., Brigidi, P., Tomé, D., Claus, S.P. and Sanz, Y., 2019. High-protein diets for weight management: interactions with the intestinal microbiota and consequences for gut health. A position paper by the my new gut study group. Clinical Nutrition 38: 1012-1022. https://doi.org/10.1016/j.clnu.2018.09.016
Bouter, K., Bakker, G.J., Levin, E., Hartstra, A.V., Kootte, R.S., Udayappan, S.D., Katiraei, S., Bahler, L., Gilijamse, P.W., Tremaroli, V., Stahlman, M., Holleman, F., Van Riel, N.A.W., Verberne, H.J., Romijn, J.A., Dallinga-Thie, G.M., Serlie, M.J., Ackermans, M.T., Kemper, E.M., Willems van Dijk, K., Backhed, F., Groen, A.K. and Nieuwdorp, M., 2018. Differential metabolic effects of oral butyrate treatment in lean versus metabolic syndrome subjects. Clinical and Translational Gastroenterology 9: 155-155. https://doi.org/10.1038/ s41424-018-0025-4

Canfora, E.E. and Blaak, E.E., 2018. Beta glucan and acetate production. Clinicaltrials.gov. Available at: https://clinicaltrials.gov/ct2/show/ NCT03714646

Canfora, E.E., Jocken, J.W. and Blaak, E.E., 2015. Short-chain fatty acids in control of body weight and insulin sensitivity. Nature Reviews Endocrinology 11: 577-591. https://doi.org/10.1038/ nrendo.2015.128

Canfora, E.E., Meex, R.C.R., Venema, K. and Blaak, E.E., 2019. Gut microbial metabolites in obesity, NAFLD and T2DM. Nature Reviews Endocrinology 15: 261-273. https://doi.org/10.1038/ s41574-019-0156-Z

Castaner, O., Goday, A., Park, Y.-M., Lee, S.-H., Magkos, F., Shiow, S.-A.T.E. and Schröder, H., 2018. The gut microbiome profile in obesity: a systematic review. International Journal of Endocrinology 2018: 4095789. https://doi.org/10.1155/2018/4095789

Da Silva, H.E., Teterina, A., Comelli, E.M., Taibi, A., Arendt, B.M., Fischer, S.E., Lou, W. and Allard, J.P., 2018. Nonalcoholic fatty liver disease is associated with dysbiosis independent of body mass index and insulin resistance. Scientific Reports 8: 1466. https:// doi.org/10.1038/s41598-018-19753-9

De Weir, J.B., 1949. New methods for calculating metabolic rate with special reference to protein metabolism. Journal of Physiology 109: 1-9.

Den Besten, G., Van Eunen, K., Groen, A.K., Venema, K., Reijngoud, D.-J. and Bakker, B.M., 2013. The role of short-chain fatty acids in the interplay between diet, gut microbiota, and host energy metabolism. Journal of Lipid Research 54: 2325-2340. https://doi. org/10.1194/jlr.R036012

Feng, W., Ao, H. and Peng, C., 2018. Gut microbiota, short-chain fatty acids, and herbal medicines. Frontiers in Pharmacology 9: 1354. https://doi.org/10.3389/fphar.2018.01354

Fernandes, J., Su, W., Rahat-Rozenbloom, S., Wolever, T.M.S. and Comelli, E.M., 2014. Adiposity, gut microbiota and faecal short chain fatty acids are linked in adult humans. Nutrition and Diabetes 4: e121. https://doi.org/10.1038/nutd.2014.23

Frayn, K.N., 1983. Calculation of substrate oxidation rates in vivo from gaseous exchange. Journal of Applied Physiology: Respiratory, Environmental and Exercise Physiology 55: 628-634. https://doi. org/10.1152/jappl.1983.55.2.628

Gannon, N.P., Schnuck, J.K. and Vaughan, R.A., 2018. BCAA metabolism and insulin sensitivity - dysregulated by metabolic status? Molecular Nutrition and Food Research 62: e1700756. https://doi.org/10.1002/mnfr.201700756 
Garcia-Villalba, R., Gimenez-Bastida, J.A., Garcia-Conesa, M.T., Tomas-Barberan, F.A., Carlos Espin, J. and Larrosa, M., 2012. Alternative method for gas chromatography-mass spectrometry analysis of short-chain fatty acids in faecal samples. Journal of Separation Science 35: 1906-1913. https://doi.org/10.1002/ jssc.201101121

Granado-Serrano, A.B., Martín-Garí, M., Sánchez, V., Riart Solans, M., Berdún, R., Ludwig, I.A., Rubió, L., Vilaprinyó, E., Portero-Otín, M. and Serrano, J.C.E., 2019. Faecal bacterial and short-chain fatty acids signature in hypercholesterolemia. Scientific Reports 9: 1772. https://doi.org/10.1038/s41598-019-38874-3

Hald, S., Schioldan, A.G., Moore, M.E., Dige, A., Lærke, H.N., Agnholt, J., Bach Knudsen, K.E., Hermansen, K., Marco, M.L., Gregersen, S. and Dahlerup, J.F., 2016. Effects of arabinoxylan and resistant starch on intestinal microbiota and short-chain fatty acids in subjects with metabolic syndrome: a randomised crossover study. PLoS ONE 11: e0159223. https://doi.org/10.1371/journal.pone.0159223

Hansen, A.M.B., Wium, C., Lee, S., Tierney, A.C., McCarthy, D., Roche, H.M., Drevon, C.A., Birkeland, K.I. and Gulseth, H.L., 2020. Substantial inter-individual variations in insulin secretion and sensitivity across the glucometabolic spectrum. Scandinavian Journal of Clinical and Laboratory Investigation 80: 282-290. https:// doi.org/10.1080/00365513.2020.1730433

Heimann, E., Nyman, M., Pålbrink, A.-K., Lindkvist-Petersson, K. and Degerman, E., 2016. Branched short-chain fatty acids modulate glucose and lipid metabolism in primary adipocytes. Adipocyte 5: 359-368. https://doi.org/10.1080/21623945.2016.1252011

Holscher, H.D., 2017. Dietary fiber and prebiotics and the gastrointestinal microbiota. Gut Microbes 8: 172-184. https://doi. org/10.1080/19490976.2017.1290756

Koh, A., De Vadder, F., Kovatcheva-Datchary, P. and Bäckhed, F., 2016. From dietary fiber to host physiology: short-chain fatty acids as key bacterial metabolites. Cell 165: 1332-1345. https://doi.org/10.1016/j. cell.2016.05.041

Koliada, A., Syzenko, G., Moseiko, V., Budovska, L., Puchkov, K., Perederiy, V., Gavalko, Y., Dorofeyev, A., Romanenko, M., Tkach, S., Sineok, L., Lushchak, O. and Vaiserman, A., 2017. Association between body mass index and Firmicutes/Bacteroidetes ratio in an adult Ukrainian population. BMC Microbiology 17: 120-120. https://doi.org/10.1186/s12866-017-1027-1

Kovatcheva-Datchary, P., Nilsson, A., Akrami, R., Lee, Y.S., De Vadder, F., Arora, T., Hallen, A., Martens, E., Björck, I. and Bäckhed, F., 2015. Dietary fiber-induced improvement in glucose metabolism is associated with increased abundance of Prevotella. Cell Metabolism 22: 971-982. https://doi.org/10.1016/j.cmet.2015.10.001

Le Roy, T., Llopis, M., Lepage, P., Bruneau, A., Rabot, S., Bevilacqua, C., Martin, P., Philippe, C., Walker, F., Bado, A., Perlemuter, G., Cassard-Doulcier, A.M. and Gerard, P., 2013. Intestinal microbiota determines development of non-alcoholic fatty liver disease in mice. Gut 62: 1787-1794. https://doi.org/10.1136/gutjnl-2012-303816

Ley, R.E., Bäckhed, F., Turnbaugh, P., Lozupone, C.A., Knight, R.D. and Gordon, J.I., 2005. Obesity alters gut microbial ecology. Proceedings of the National Academy of Sciences of the USA 102: 11070-11075. https://doi.org/10.1073/pnas.0504978102
Lim, J., Henry, C.J. and Haldar, S., 2016. Vinegar as a functional ingredient to improve postprandial glycemic control-human intervention findings and molecular mechanisms. Molecular Nutrition and Food Research 60: 1837-1849. https://doi.org/10.1002/ mnfr.201600121

Mariat, D., Firmesse, O., Levenez, F., Guimarăes, V.D., Sokol, H., Doré, J., Corthier, G. and Furet, J.P., 2009. The Firmicutes/Bacteroidetes ratio of the human microbiota changes with age. BMC Microbiology 9: 123. https://doi.org/10.1186/1471-2180-9-123

Matthews, D.R., Hosker, J.P., Rudenski, A.S., Naylor, B.A., Treacher, D.F. and Turner, R.C., 1985. Homeostasis model assessment: insulin resistance and beta-cell function from fasting plasma glucose and insulin concentrations in man. Diabetologia 28: 412-419. https:// doi.org/10.1007/bf00280883

Mika, A., Stepnowski, P., Kaska, L., Proczko, M., Wisniewski, P., Sledzinski, M. and Sledzinski, T., 2016. A comprehensive study of serum odd-and branched-chain fatty acids in patients with excess weight. Obesity 24: 1669-1676. https://doi.org/10.1002/oby.21560

Müller, M., Canfora, E.E. and Blaak, E.E., 2018. Gastrointestinal transit time, glucose homeostasis and metabolic health: modulation by dietary fibers. Nutrients 10: 275. https://doi.org/10.3390/ nu10030275

Müller, M., Hermes, G., Canfora, E., Holst, J., Zoetendal, E., Smidt, H., Troost, F., Schaap, F., Damink, S., Jocken, J., Lenaerts, K., Masclee, A. and Blaak, E., 2020. Effect of wheat bran derived prebiotic supplementation on gastrointestinal transit, gut microbiota, and metabolic health: a randomized controlled trial in healthy adults with a slow gut transit. Gut Microbes 12: 1704141. https://doi.org /10.1080/19490976.2019.1704141

Müller, M., Hernández, M.A.G., Goossens, G.H., Reijnders, D., Holst, J.J., Jocken, J.W.E., Van Eijk, H., Canfora, E.E. and Blaak, E.E., 2019. Circulating but not faecal short-chain fatty acids are related to insulin sensitivity, lipolysis and GLP-1 concentrations in humans. Scientific Reports 9: 12515. https://doi.org/10.1038/s41598-01948775-0

Nagpal, R., Mainali, R., Ahmadi, S., Wang, S., Singh, R., Kavanagh, K., Kitzman, D.W., Kushugulova, A., Marotta, F. and Yadav, H., 2018. Gut microbiome and aging: physiological and mechanistic insights. Nutrition and Healthy Aging 4: 267-285. https://doi.org/10.3233/ NHA-170030

Newgard, C.B., An, J., Bain, J.R., Muehlbauer, M.J., Stevens, R.D., Lien, L.F., Haqq, A.M., Shah, S.H., Arlotto, M., Slentz, C.A., Rochon, J., Gallup, D., Ilkayeva, O., Wenner, B.R., Yancy Jr, W.S., Eisenson, H., Musante, G., Surwit, R.S., Millington, D.S., Butler, M.D. and Svetkey, L.P., 2009. A branched-chain amino acid-related metabolic signature that differentiates obese and lean humans and contributes to insulin resistance. Cell Metabolism 9: 311-326. https://doi.org/10.1016/j. cmet.2009.02.002

Ran-Ressler, R.R., Bae, S., Lawrence, P., Wang, D.H. and Brenna, J.T., 2014. Branched-chain fatty acid content of foods and estimated intake in the USA. British Journal of Nutrition 112: 565-572. https:// doi.org/10.1017/s0007114514001081 
Ridaura, V.K., Faith, J.J., Rey, F.E., Cheng, J., Duncan, A.E., Kau, A.L., Griffin, N.W., Lombard, V., Henrissat, B., Bain, J.R., Muehlbauer, M.J., Ilkayeva, O., Semenkovich, C.F., Funai, K., Hayashi, D.K., Lyle, B.J., Martini, M.C., Ursell, L.K., Clemente, J.C., Van Treuren, W., Walters, W.A., Knight, R., Newgard, C.B., Heath, A.C. and Gordon, J.I., 2013. Gut microbiota from twins discordant for obesity modulate metabolism in mice. Science 341: 1241214. https://doi. org/10.1126/science.1241214

Russell, W.R., Gratz, S.W., Duncan, S.H., Holtrop, G., Ince, J., Scobbie, L., Duncan, G., Johnstone, A.M., Lobley, G.E., Wallace, R.J., Duthie, G.G. and Flint, H.J., 2011. High-protein, reduced-carbohydrate weight-loss diets promote metabolite profiles likely to be detrimental to colonic health. American Journal of Clinical Nutrition 93: 10621072. https://doi.org/10.3945/ajcn.110.002188

Schwiertz, A., Taras, D., Schäfer, K., Beijer, S., Bos, N.A., Donus, C. and Hardt, P.D., 2010. Microbiota and SCFA in lean and overweight healthy subjects. Obesity 18: 190-195. https://doi.org/10.1038/ oby. 2009.167

Shen, J., Obin, M.S. and Zhao, L., 2013. The gut microbiota, obesity and insulin resistance. Molecular Aspects of Medicine 34: 39-58. https://doi.org/10.1016/j.mam.2012.11.001

Tang, Z.-Z., Chen, G., Hong, Q., Huang, S., Smith, H.M., Shah, R.D., Scholz, M. and Ferguson, J.F., 2019. Multi-omic analysis of the microbiome and metabolome in healthy subjects reveals microbiome-dependent relationships between diet and metabolites. Frontiers in Genetics 10: 454. https://doi.org/10.3389/ fgene.2019.00454

Tiihonen, K., Ouwehand, A.C. and Rautonen, N., 2010. Effect of overweight on gastrointestinal microbiology and immunology: correlation with blood biomarkers. British Journal of Nutrition 103: 1070-1078. https://doi.org/10.1017/S0007114509992807
Turnbaugh, P.J., Ley, R.E., Mahowald, M.A., Magrini, V., Mardis, E.R. and Gordon, J.I., 2006. An obesity-associated gut microbiome with increased capacity for energy harvest. Nature 444: 1027-1031. https://doi.org/10.1038/nature05414

Van der Beek, C.M., Canfora, E.E., Kip, A.M., Gorissen, S.H.M., Olde Damink, S.W.M., Van Eijk, H.M., Holst, J.J., Blaak, E.E., Dejong, C.H.C. and Lenaerts, K., 2018. The prebiotic inulin improves substrate metabolism and promotes short-chain fatty acid production in overweight to obese men. Metabolism 87: 25-35. https://doi.org/10.1016/j.metabol.2018.06.009

Vogelzangs, N., Van der Kallen, C.J.H., Van Greevenbroek, M.M.J., Van der Kolk, B.W., Jocken, J.W.E., Goossens, G.H., Schaper, N.C., Henry, R.M.A., Eussen, S.J.P.M., Valsesia, A., Hankemeier, T., Astrup, A., Saris, W.H.M., Stehouwer, C.D.A., Blaak, E.E., Arts, I.C.W. and the Diogenes Consortium., 2020. Metabolic profiling of tissue-specific insulin resistance in human obesity: results from the Diogenes study and the Maastricht Study. International Journal of Obesity 44: 1376-1386. https://doi.org/10.1038/s41366-020-0565-Z

Wu, G.D., Chen, J., Hoffmann, C., Bittinger, K., Chen, Y.-Y., Keilbaugh, S.A., Bewtra, M., Knights, D., Walters, W.A., Knight, R., Sinha, R., Gilroy, E., Gupta, K., Baldassano, R., Nessel, L., Li, H., Bushman, F.D. and Lewis, J.D., 2011. Linking long-term dietary patterns with gut microbial enterotypes. Science 334: 105. https://doi.org/10.1126/ science.1208344

Zhong, H., Penders, J., Shi, Z., Ren, H., Cai, K., Fang, C., Ding, Q., Thijs, C., Blaak, E.E., Stehouwer, C.D.A., Xu, X., Yang, H., Wang, J., Wang, J., Jonkers, D.M.A.E., Masclee, A.A.M., Brix, S., Li, J., Arts, I.C.W. and Kristiansen, K., 2019. Impact of early events and lifestyle on the gut microbiota and metabolic phenotypes in young school-age children. Microbiome 7: 2. https://doi.org/10.1186/ s40168-018-0608-Z 